Article

\title{
Addressing Modern Slavery in the IB Classroom: Are We Doing Enough?
}

\author{
Swati Nagar ${ }^{1}$, Fiona Hurd ${ }^{1}$ \\ ${ }^{1}$ Auckland University of Technology, New Zealand \\ Keywords: action guide, learning, teaching, ib classroom, modern slavery \\ https://doi.org/10.46697/001c.13543
}

\section{AIB Insights}

Vol. 20, Issue 2, 2020

The current literature on modern slavery in IB teaching and research is rather limited. Even in adopting case discussions in the classroom, it is challenging to find resources that highlight an IB context. The challenge, therefore, lies both in the pedagogical motivation to develop teaching strategies and resources as well as undertaking research that helps fill the current literature gap regarding modern slavery. This paper presents a discussion on the importance of developing teaching resources, supported by relevant examples that address modern slavery in the IB classroom.

\section{INTRODUCTION}

Modern slavery is a broad term that comprises activities including bonded and forced labor, human trafficking, and other forms of commercial exploitation (Burmester, Michailova, \& Stringer, 2019; Stringer \& Michailova, 2018). While modern slavery is present in all countries, the largest proportion of it, approximately $64 \%$, is employed in forced labor situations in developing countries in the Asia-Pacific region (ILO, 2017), a region that is of significant importance to multinational enterprises (MNE), and by extension, to international business (IB) scholars.

The availability of lower labor costs has meant that many MNEs have relocated their operational activities, particularly to some of the largest economies in the Asia-Pacific region, to maintain competitiveness on a global scale. The region, therefore, plays a critical role within MNEs' global value chains (GVCs). However, many economies in the region suffer from inadequate institutional frameworks and policies, which means the workers employed within GVCs often lack job security and are unaware of their rights, making them more vulnerable to exploitation. According to an ILO report (2017), the Asia-Pacific region, for example, has one the highest prevalence of forced labour (4.0 workers per 1000 people) in the world. Sectors that employ forced labour in the Asia-Pacific region primarily include construction, manufacturing, agriculture, forestry, and fisheries (ILO, 2017). Also, the complexity of GVC sub-contracting networks means that worker exploitation can be obscured and often hidden from the public eye, making it difficult to monitor and report such activities (Stringer \& Michailova, 2018).

The current literature on modern slavery in IB teaching and research is rather limited. For example, in our search of Harvard Business cases, of 21,932 cases, we identified only 129 cases that are in the IB discipline (examples included GVCs and worker exploitation), representing just $0.6 \%$ of the total number. Of these, just 15 returned with a keyword "modern slavery," "ethical practice” or "international outsourcing." To address such issues in the IB classroom, presently, many of us revert to either adapting generic business cases for the IB context or utilize academic work, often not written for IB teaching purposes. Even in adopting case discussions in the classroom, it is challenging to find resources that highlight an IB context. The challenge, there- fore, lies both in the pedagogical motivation to develop teaching strategies and resources as well as undertaking research that helps fill the current literature gap regarding modern slavery (Crane, Matten, \& Spence, 2013).

Recognizing this, we first highlight the paucity of articles that currently prevails in the IB literature on modern slavery. The second section of the paper presents a discussion on the importance of developing teaching resources, supported by relevant examples that address modern slavery in the IB classroom. While we fully acknowledge the previous work done in the area of modern slavery, in this paper, we only give examples of our contributions. We offer some initial action guides with the hope of facilitating further discussion in this area.

\section{DISCUSSING MODERN SLAVERY IN THE IB CLASSROOM}

As IB academics, we are mindful of both institutional and industry calls to ensure our students understand and are prepared to respond to ethical issues that are particularly prevalent in an IB context. These calls are not new, starting with concerns around sweatshop practices during the 1990s and heightened with calls for a paradigm shift in IB dating back to a decade ago (Holland, 2009).

In response, the Principles of Responsible Management Education (PRME), a UN Compact initiative driven by both business school deans and the corporate sector, was developed in 2007. This initiative aimed to ensure business schools provide future leaders with the skills needed to balance economic and sustainability goals; to equip today's business students with the understanding and ability to deliver change tomorrow. Based on six principles, the PRME not only recommends the nature of the content universities will cover with students but also suggests how universities will lead the discussion among industry members around issues of social and environmental sustainability. Currently, there are 790 signatories worldwide to the PRME. It is within a PRME signatory context that we teach a range of IB courses at our university. The aim is to engage students with a critical understanding of not only IB practices but also key ethical challenges (for example, modern slavery) that arise when doing business internationally.

To encourage deep learning, we often employ a "learning by doing" strategy in our courses. This is achieved through 
the engagement of both theoretical and applied content, especially when addressing topics on corporate social responsibility, ethical conduct, labor abuse and exploitation, and the role of GVCs. Although these topics feature in the IB curricula, the availability of data is an issue. For example, disciplines of organizational behavior, supply chain management, and ethics often have a range of case-based examples as well as journal and editorial articles that discuss such aspects. However, it is often challenging to apply the literature from those sources in an IB classroom. This paucity of materials is perhaps because the frameworks and the mainstream IB literature do not sufficiently address the "dark side" of globalization.

The limited availability of mainstream academic research and teaching resources means that IB academics often use examples covered in the media. Some of the most prominent examples include (but are not limited to) forced labor in the fishing industry, labor exploitation in the mining of materials for use in the global electronics industries, poor working conditions observed in the ready-made garment industry and labor practices in the construction sector. The nature of the material in the media also means that class debates on how the need and the desire to achieve the triple bottom line relates to firm strategy and the broader institutional environment, which are potentially the driving force behind modern slavery, remain largely superficial. From a pedagogical perspective, the scarcity of IB academic research and teaching resources on such topics makes it challenging to create awareness and much-needed critical reasoning skills among the IB student body.

Supporting this view, Nastase and Gligor-Cimpoieru (2013) state that IB instructors often have a minimal available set of resources that specifically address ethical challenges firms face when operating internationally. It is in this context that students often analyze and respond to complex issues (such as modern slavery), challenges and consumer preferences, often a prerequisite to business survival. Martin et al. (2011) concur and advocate that the relative lack of focus on pedagogical strategy and research in the field has resulted in IB courses largely focusing on the MNE, with little acknowledgement of wider ethical issues that may arise as a result of MNE operations. This is particularly concerning, given that issues such as modern slavery are facilitated by, and benefit IB activities. This highlights the need for more attention to how, as a discipline, we approach IB academic research and teaching with an ethically focused lens and awareness of the existence of modern slavery.

\section{WHAT CAN AND SHOULD WE CHANGE?}

As noted earlier, while there have been widespread calls for changes to IB curricula, as a discipline, we have been relatively hesitant to incorporate into our research and teaching resources the topic of modern slavery and its prevalence in IB. Recognizing this, we call for new contributions both in research and teaching material to better equip our students to comprehend the challenges inevitably entwined with IB. Such curricula should not only be located in our own contexts but should also include examples from both developed and developing economies where ethical challenges are prevalent and concurrently affect MNEs, international labor markets and institutions. As a minor contribution to fill the existing gap, we have recently published an experiential case-study in the Journal of International Business Education (Hurd \& Nagar, 2019). Using the context of the ready-made garment industry in Cambodia, the case helps IB students understand, through an ethically focused lens, real-world challenges (including modern slavery) that MNEs encounter within GVCs. The case presents four distinct phases, where students must evaluate the benefits of outsourcing garment production alongside the exploitation occurring in the industry (and reduction in the local manufacturing workforce).

Through the case, students have an opportunity to engage in deeper learning of the international system of human rights, fair work practices and labor protection concerning exploitation that occurs, especially in GVCs. In doing so, we introduce the students to key frameworks and organizations (such as PRME, UN Global Compact and OECD Guidelines for MNEs) that encourage and in some cases mandate, ethical corporate behavior. Finally, the students are required to form a proposal on the best corporate practice and present it to the firm's management. Although written from a New Zealand perspective, the case can be used in other contexts as it encompasses activities that may be useful across a range of courses that may address the varied aspects of modern slavery.

Additionally, we have also found non-traditional assessment strategies such as blogs, poster boards, and video presentations particularly useful to encourage student interaction in class. For example, in one of our postgraduate courses, students are asked to choose an industry that is known for modern slavery (such as fish processing or electronics manufacturing) and present a poster board to the class, highlighting the severity of the situation in the chosen industry. Students are also encouraged to present information on legal frameworks/policies designed to prohibit modern slavery and the effect these have had on their chosen industry. The intention here is to develop an understanding of the influence that legal institutions have (or not) on human rights protection. Based on our previous work on the use of non-traditional assessment strategies when addressing issues (such as modern slavery) adopting a critical perspective, we have received an invite to present our teaching and learning strategies at the AIB 2020 Teaching \& Education Professional Development Workshop. This workshop aims to engage with fellow academics to expand pedagogical strategies used in the IB classroom through hands-on exposure to a range of experiential learning activities.

The discussion so far highlights two critical gaps that currently exist: a general lack of teaching resources and experiential activities currently utilized to educate students on modern slavery and a limited discussion on these topics within mainstream IB scholarship. We propose the following strategies with the hope of encouraging further dialogue among fellow IB academics.

\section{DEVELOPING A COLLECTIVE TEACHING RESOURCES REPOSITORY}

We call for the development of a wider variety of accessible teaching material and experiential activities that can be employed in the IB classroom to encourage analysis of modern slavery and related crimes. For this, we propose a collective repository developed by IB academics. The purpose would be to host a collection of teaching material, cases, media articles, industry and government reports that specifically address the topic of modern slavery from an IB viewpoint. The repository can be made available to all AIB members so that they can make use of the resources as required. For example, such a repository can be created on the $A I B$ Insights landing page. In doing so, it will allow conve- 
nient access to teaching material and related resources from a common platform. Additionally, the repository could also allow IB instructors to collaborate with peers from other universities to create simulations where students, both undergraduate and postgraduate, discuss industry-specific 'real-life' issues associated with modern slavery. The purpose of such simulations would be to facilitate more significant interaction and dialogue both in the classroom and amongst fellow IB academics. Moreover, by embedding such approaches in mainstream IB, we are positioning such issues as central to IB activities.

\section{NEW COURSE DEVELOPMENT}

We suggest the development of "Modern Slavery in a Global Context" IB courses. The purpose of such a course would be to specifically address themes such as the connection of increased global economic development and the growth of modern slavery, issues associated with class and gender in modern slavery as well as the significance of the national and international legal frameworks and their impact on modern slavery. While there are courses on slavery offered by several universities internationally, most address the historic transatlantic trade and slavery with minimal discussion on modern slavery and its prevalence in IB (Hampton, 2019). Also, the debate on such issues in business schools is addressed predominantly by the Management discipline, specifically in the areas of supply chain management, organizational behavior, and ethics. Limited acknowledgement of IB issues from a critical perspective, therefore, makes it difficult for the faculty to challenge students' preconceptions of slavery as a historical phenomenon. Considering this, we suggest that IB academics connect (via a common platform linked to the repository) to exchange ideas for new courses and topics that specifically address modern slavery as an IB phenomenon.

\section{FURTHER ACADEMIC RESEARCH ON MODERN SLAVERY}

Greater awareness and understanding of modern slavery within mainstream IB education would benefit from increased academic research in the area. To further develop this line of important and timely inquiry, it is paramount to create and pursue research and publication opportunities within mainstream IB on such a serious crime as modern slavery. While there is valuable research that currently ad- dresses such issues (for example, Journal of Business Ethics and critical perspectives on international business), there is a strong need for further studies on these topics. Therefore, we propose dedicated special issues in mainstream research- and education-focused IB journals that can further this research agenda. Similarly, dedicated conference tracks at annual AIB conferences, regional AIB Chapter meetings, and doctoral consortia can open new avenues for IB academics to present and discuss their research in the area. Such research avenues can further promote evidence-based studies on the role of MNEs, GVCs, and industry in enabling modern slavery, the rise of ethical consumerism, and policies/strategies designed to prohibit such practices. For without such research, any attempt to promote further dialogue on this vital issue may fail to gain attention within the mainstream IB literature.

We hope that this paper sparks further discussion and development of new teaching material and research to incorporate the issue of modern slavery in the IB classroom. We also encourage fellow IB educators and researchers to reflect on the broader impacts of MNE activities and consider the role we can play in informing the development of responsible business practices.

\section{ABOUT THE AUTHORS}

Swati Nagar (swati.nagar@aut.ac.nz) is a Lecturer in the Department of International Business, Strategy and Entrepreneurship at Auckland University of Technology, New Zealand. Her current research interests lie in two areas - examining the nature and extent of labor exploitation present in global value chains and understanding the relationship between student characteristics and experiential learning in executive education. She has previously published pedagogical studies in Palgrave and Journal of International Business Education.

Fiona Hurd (fiona.hurd@aut.ac.nz) is a Senior Lecturer in the Department of International Business, Strategy and Entrepreneurship at Auckland University of Technology, New Zealand. She has a key research interest in pedagogies for engagement, in particular critical and democratic pedagogies which move students from surface to deep learning. She has previously published pedagogical studies in Academy of Management Learning and Education, Gender and Education and Equality, Diversity and Inclusion. 


\section{REFERENCES}

Burmester, B., Michailova, S., \& Stringer, C. 2019. Modern slavery and international business scholarship: The governance nexus. Critical Perspectives on International Business, 15(2/3): 139-157.

Crane, A., Matten, D., \& Spence, L. J. 2013. Corporate social responsibility: Readings and cases in a global context. Abingdon: Routledge.

Hampton, D. B. 2019. Modern slavery in global supply chains: Can national action plans on business and human rights close the governance gap? Business and Human Rights Journal, 4(2): 239-263.

Holland, H. 2009. Is it time to retrain B-schools. New York Times. https://www.nytimes.com/2009/03/15/bu siness/15school.html.

Hurd, F., \& Nagar, S. 2019. Bringing the PRME into the international business classroom: An experiential exercise in ethical decision-making in the New Zealand context. Journal of International Business Education, 14: 245-264.
ILO. 2017. Global estimates of modern slavery: Forced labour and forced marriage. https://www.ilo.org/wcms p5/groups/public/---dgreports/dcomm/documents/pu blications/wcms 575479.pdf.

Martin, J. A., Heppard, K. A., \& Green, S. G. 2011. Taking international business education programs and pedagogy to new heights: Fundamental questions for educators and students. Business Horizons, 54(4): $355-363$.

Nastase, M., \& Gligor-Cimpoieru, D. C. 2013. A plea for the importance of business ethics education for future managers in an international competitive environment. Review of International Comparative Management, 14(2): 191-201.

Stringer, C., \& Michailova, S. 2018. Why modern slavery thrives in multinational corporations' global value chains. Multinational Business Review, 26(3): 194-206. 